\title{
Endoscopic balloon dilatation of acquired airway stenosis in newborn infants: a promising treatment
}

\section{Department of Paediatrics, Paediatric Clinic, University Hospital Groningen, Groningen, The Netherlands S C Elkerbout \\ Division of Neonatology Division of Paediatric Pulmonology J Gerritsen \\ Correspondence to: Dr S C Elkerbout, Paediatric Clinic, Sophia Hospital, PO Box 10400,8000 GK Zwolle, The Netherlands.}

Accepted 13 August 1992

\begin{abstract}
Acquired stenosis of the trachea or bronchus in newborn infants is a possible complication of perinatal intubation and mechanical ventilation. Although the exact pathophysiology is unknown, stenosis formation seems to be initiated by pressure necrosis. Prematurity is thought to be an important risk factor for acquired airway stenosis. Management of stenotic lesions may be conservative, surgical, or endoscopic. Four patients were treated with endoscopic balloon dilatation with satisfactory results. Endoscopic balloon dilatation is the method of choice in most newborn infants with acquired bronchial or tracheal stenosis.
\end{abstract}

(Arch Dis Child 1993;68:37-40)

Acquired tracheal or bronchial stenosis may cause severe respiratory problems in newborn infants ventilated because of respiratory distress. In its most serious form it may result in prolonged mechanical ventilation, because all attempts to wean the affected neonate from the ventilator will fail. Four newborn infants with these problems are presented. A noninvasive endoscopic procedure for dilatation of acquired tracheal or bronchial stenosis is discussed, as are some recommendations for prevention.

\section{Case reports}

PATIENT 1

This patient was a newborn infant of 30 weeks' gestation. Owing to perinatal asphyxia, she was intubated and mechanically ventilated for one week. Within a few days after extubation, however, she developed respiratory insufficiency for which she was reintubated and again mechanically ventilated. Chest radiographs showed recurring atelectasis on both sides, hyperlucent areas, and a variable mediastinal shift. Despite intensive treatment, these severe abnormalities persisted.

Bronchoscopy performed at the age of 4 weeks showed a right and left main bronchus which were too narrow to introduce the bronchoscope into the lumen. Bronchography showed a relatively long bilateral segmental stenosis in the main bronchi as well as an obstruction of the bronchus of the right lower lobe. We performed bronchoscopic balloon dilatation of the left main bronchus three times at one week intervals. At follow up bronchography an almost normal lumen of the left main bronchus was seen. In the nondilated right main bronchus, a stenosis, though less serious, persisted. One day after the final dilatation, the girl was definitively extubated.

Respiratory infections with inspiratory stridor and wheezing often occurred during her first year and again after an interval of two years without symptoms. Recently bronchoscopic balloon dilatation of the right main bronchus has been performed, with good results.

\section{PATIENT 2}

A newborn infant of 30 weeks' gestation developed a respiratory distress syndrome associated with hyaline membrane disease stage $3 / 4$, for which she was intubated and mechanically ventilated for one week. Ten days after the first extubation she was reintubated because of respiratory insufficiency, now associated with an aspiration pneumonia. She had recurring atelectasis, mainly on the right side. Bronchoscopy showed a swollen, inflamed tracheal mucosa, which caused a stenosis of the trachea near the carina. Conservative treatment resulted in a dramatic improvement of the tracheal stenosis, as shown by bronchoscopy a few days later. Distal to this stricture, however, a stenosis of the right main bronchus was seen. As a third attempt at extubation failed, we performed a bronchoscopic balloon dilatation of the right main bronchus at the age of 3.5 months. The next day the girl was successfully weaned from the ventilator and extubated. Bronchoscopy one week and two and a half months after dilatation was satisfactory, showing a weblike structure which caused only minimal stenosis. At the age of 19 months the girl is doing well without evident respiratory symptoms.

PATIENT 3

A term newborn infant of $2100 \mathrm{~g}$ developed sepsis, complicated by cardiorespiratory insufficiency. He was supported with mechanical ventilation for more than one week. After extubation the respiratory problems continued with recurring atelectasis, mainly on the right side. Three weeks later this resulted in a sudden deterioration, for which mechanical ventilation was reinstituted.

Bronchoscopy showed a cicatricial narrowing of the distal trachea, a serious stenosis of the right main bronchus, and to a lesser degree of the left bronchus. During a second bronchoscopy the distal trachea and right main bronchus were carefully dilated by a rigid bronchoscope. After this procedure the 
boy was weaned and extubated; however, this lasted for less than one week. The next bronchoscopy showed a persistent severe stenosis of the right main bronchus, which now was treated by balloon dilatation. At follow up bronchoscopy granulation tissue was present in the right main bronchus. The same day the boy developed symptoms consistent with sepsis. Despite maximum support he died of cardiovascular insufficiency. Necropsy confirmed a stenosis of the right main bronchus, multiple stenosis of the right lobar bronchi, and bronchopneumonia.

PATIENT 4

A newborn infant of 29 weeks' gestation was intubated and mechanically ventilated due to perinatal asphyxia. After one week she had developed atelectasis on both the right and left side. Nevertheless, she was weaned from the ventilator and successfully extubated. Ten days later, however, she again developed a short term need for ventilatory support.

As atelectasis persisted, a bronchoscopy and bronchography were performed, showing a stenosis of the left main bronchus. After bronchography the patient had hypoventilation due to a bronchospasm and plug formation obstructing the stenosis. For the third time she was intubated and mechanically ventilated. As a result of severe hypoxia while ventilated, an emergency bronchoscopy was performed at the age of 9 weeks. Subsequently a balloon dilatation of the left main bronchus was performed. After one week the procedure was repeated and approximately two weeks later the patient was extubated.

She is now 1 year old. Bronchoscopy has not yet been repeated because of her satisfactory clinical condition.

Method of endoscopic balloon dilatation of acquired tracheal or bronchial stenosis Dilatations were performed under general anaesthesia. All the patients were already endotracheally intubated and ventilated. Before the procedure they were hyperventilated with $100 \%$ oxygen. Their endotracheal tube was replaced by a 3.0 or $3.5 \mathrm{~mm}$ Storz-Hopkins rigid bronchoscope. A Fogarty arterial embolectomy catheter (Edwards, Santa Ana, CA, USA) was inserted under direct vision and positioned in the stenotic segment. The size of the chosen catheter depended on estimations of the calibre of the airway proximal to and at the stenosis. If bronchographic data were available the length of the stenosis also played a part in selecting the size of the balloon catheter. We used 3 and 5 French catheters, with balloons 5 and $11 \mathrm{~mm}$ in diameter, and a gas capacity of 0.6 and $3.0 \mathrm{ml}$ respectively. Inflation of the balloon was performed with air to the maximum capacity for 15 to $30 \mathrm{sec}$ onds. If the intervention did not result in a minimal increase in the calibre of the stenosis, the procedure was repeated after an interval of two to three minutes to allow for the recovery of the patient. At the end of the procedure the endotracheal tube was replaced and intravenous steroids were given for 48 hours.

\section{Discussion}

We have presented the cases of four newborn infants who developed bronchotracheal stenosis after or during mechanical ventilation. Endotracheal intubation and mechanical ventilation in newborn infants may lead to long term complications, of which acquired tracheal stenosis or acquired bronchial stenosis are important. As a result of the increased use of mechanical ventilation in the last 25 years, especially in preterm newborn infants, the incidence of acquired tracheal stenosis has risen equally. ${ }^{1-3}$ Estimates vary from around $2 \%{ }^{45}$ to $4-11 \% .^{6}$ The incidence of acquired bronchial stenosis is unknown, but it is being recognised more often due to the increased use of bronchoscopy. ${ }^{7}$

\section{PATHOPHYSIOLOGY}

The pathophysiology of acquired tracheal or bronchial stenosis is not exactly clear. Several necropsy studies have led to the suggestion that in the first hours or days of intubation, the endotracheal tube may initiate a pressure necrosis in the trachea or bronchus, resulting in oedema and ulceration. ${ }^{3}$ Trauma from suction catheters may have the same effect. ${ }^{7}$ Secondary infection and perichondritis, usually progressing to chondritis and cartilaginous necrosis, cause further damage. ${ }^{3}$ A period of healing begins, with epithelial regeneration and complete re-epithelialisation within a few weeks. ${ }^{8}$ It is assumed, however, that in some instants it will result in a fibrous stricture. After full thickness necrosis of the tracheal mucosa, collapse of the framework of the larynx may also occur. ${ }^{28}$

\section{RISK FACTORS}

Risk factors in developing acquired tracheal or bronchial stenosis are numerous (table) and their effect is often synergistic: As endotracheal intubation plays an important part in the pathogenesis of acquired tracheal or bronchial stenosis, it is not surprising that low birth weight $(<1500 \mathrm{~g})$, often associated with an immature respiratory system and therefore a high need for ventilatory support, seems to be an important risk factor. ${ }^{4}$ The small size and more vulnerable structure of the airways of premature newborn infants offer another explanation for their susceptibility to acquired tracheal or bronchial stenosis. ${ }^{4}$

Prolonged intubation is said to be a major factor in the pathogenesis of acquired tracheal or bronchial stenosis. ${ }^{3} 610$ The definition of 'prolonged' in different studies, however,

Risk factors in the development of acquired tracheal or bronchial stenosis

\section{Low birth weight $(<1500 \mathrm{~g})$}

Duration of intubation ( $>50$ days)

Tube size

Tube motion

Suction procedures

General status

Infection 
varies from 72 hours to seven days and even 56 days. One study concluded that the duration of intubation was not as important a risk factor as previously thought, providing other factors were minimised by intensive medical and nursing care. ${ }^{4}$ The duration of intubation beyond 50 days may, however, play a major part. One worker reports an acquired bronchial stenosis resulting from displacement of an endotracheal tube which lasted for two hours only. ${ }^{11}$

Tube size plays a part $^{310}$; a decreasing incidence of acquired tracheal stenosis was documented when using an appropriate sized tube. ${ }^{6}$ Tube motion and frequent traumatic intubation cause damage to the tracheobronchial mucosa and as such may contribute to the development of acquired tracheal or bronchial stenosis. Some workers prefer the more stable nasal intubation method ${ }^{6}{ }^{12}$; others prefer the route by mouth, combined with a good method for tube fixation. ${ }^{13}$ They feel that the technically more difficult nasal intubation may be more traumatic, leading to more mucosal injury. ${ }^{214}$ Suction procedures with catheters passing beyond the endotracheal tube are likely to be another unfavourable factor. ${ }^{9} 15$

The general status of the patient may play a part in the pathogenesis of acquired tracheal or bronchial stenosis ${ }^{10}{ }^{16}$; for example, shock with or without sepsis may lead to ischaemic necrosis of the mucosa of the bronchus or trachea. Probably local chronic infection, after mucosal injury, plays a secondary part in the process of scar formation in the airway. ${ }^{416}$

\section{DIAGNOSIS}

The awareness that ventilation is a risk factor in developing acquired tracheal or bronchial stenosis, especially in preterm newborn infants, is the first step in its diagnosis. In the case of localised alternating hypoinflation and hyperinflation, atelectasis, stridor, or apnoea, a stenosis should be suspected. ${ }^{12} 1718$ In ventilated (premature) newborn infants, unexplained increases in ventilatory or oxygen requirements, or unexplained failure of pulmonary treatment may be a manifestation of a developing obstructive pathology. ${ }^{19}$

Whether a rigid or flexible bronchoscope is used to establish the final diagnosis is more or less a matter of preference. ${ }^{172021}$ In our clinic we prefer a rigid bronchoscope for its better view, its better continuous ventilation possibilities, and the possibility of combining it with treatment interventions if necessary. Bronchography is not always required and should be reserved for those patients in whom the distal trachea or the main bronchi cannot be seen, to establish the site and the length of the stenotic segment(s).

\section{METHODS OF TREATMENT}

Methods of treatment of acquired tracheal or bronchial stenosis can be divided into conservative measures, endoscopic, and surgical approaches. In general, conservative measures will only be supportive, though in some instances they may be curative. Judgment must be reserved towards surgical treatment: surgical reconstruction is indicated if all conservative efforts have been made $^{1}$ and if endoscopic treatment has failed or has a high likelihood of failure. ${ }^{22}$

\section{Acquired tracheal stenosis}

Tracheotomy used to be the method of choice for (temporary) treatment and even prevention of acquired tracheal stenosis. ${ }^{12} 16$ It is, however, difficult in small preterm newborn infants and its morbidity is, though declining, still high. ${ }^{5}$ Mortality rates range from 8 to $24 \% .^{2512}$ Tracheotomy for acquired tracheal stenosis is now only recommended as an emergency procedure to secure the airway, ${ }^{3}$ or after the failure of surgical procedures. ${ }^{4} 23$ First alternatives to tracheotomy were the anterior cricoid split and the cartilage graft tracheoplasty. ${ }^{12222425}$ The formation of granulation tissue is a common complication of these procedures. ${ }^{112}$

\section{Acquired tracheal stenosis/acquired bronchial stenosis}

Resection of a stenotic segment, with end to end anastomosis and, if necessary, interposition of bone or cartilage, is the only surgical procedure suitable for acquired tracheal stenosis and acquired bronchial stenosis.

Of the endoscopic techniques the most traditional is the forceps resection. Its use in newborn infants may be difficult and hazardous, often leading to bleeding or even perforation. ${ }^{7}$ Cryosurgery, an experimental technique, may result in damage of the tracheobronchial cartilage. ${ }^{26}$ Sometimes stenting of the trachea or bronchus is necessary. ${ }^{12}$ As a result of the recent development of small quartz fibreoptic cables for the argon laser, carbon dioxide laser excision can be performed in newborn infants. This difficult technique, however, is restricted to small areas and often requires multiple treatments. ${ }^{7} 12$

Balloon dilatation with an angioplasty catheter is a relatively new method. To date four workers have described successful interventions in neonates and children ranging from 1.5 to 28 months. ${ }^{15} 26-28$ Balloon dilatation is non-invasive and easy to perform compared with other endoscopic techniques. Moreover, it is applicable in low birthweight newborn infants and in sick premature infants who would not survive an operation. ${ }^{27}$ Balloon dilatation might also be an alternative after the failure of surgical intervention. ${ }^{28}$ The method is most suited for short to moderate segment acquired tracheal or bronchial stenosis, but is of no value in those forms which are mainly caused by a tight cartilage ring, as cartilage cannot be stretched. ${ }^{28}$ In some forms of congenital stenosis with a narrowing at the cricoid, however, this technique has been successful. Brown et al recommend it as the initial form of treatment for tracheobronchial stenosis in newborn infants, even in the presence of complex stenotic lesions. ${ }^{15}$ In the case of severe coexisting damage to the cricoid, surgical techniques are the method of choice. 
Theoretically, complications might be perforation and airway rupture, but neither has been reported so far. Rupture of the balloon itself, resulting in aspiration of the contents, has been described once, without sequelae. ${ }^{15}$ In our department we simply use air for insufflating the balloon, with good results. Bronchospasm sometimes develops after balloon dilatation treatment, ${ }^{15} 28$ probably as a complication of the preceding bronchography, rather than the dilatation itself. In one of our patients, bronchospasm occurred after bronchography, but not after two subsequent dilatations.

Steroids and antibiotics are conservative tools in the management of acquired tracheal or bronchial stenosis. The use of steroids is controversial. It is known that steroids decrease the inflammatory response $\mathrm{r}^{311}$ and may lead to regression and even resolution of granulation tissue. ${ }^{1729}$ On the other hand, once granulation tissue has become epithelialised, the effect of steroids is disappointing. ${ }^{72}$ Moreover, steroids may even be harmful in retarding the ingrowth of epithelium and therefore healing, ${ }^{312}$ or in increasing the absorption of cartilage in the presence of cartilage destruction. ${ }^{29}$ Nevertheless, the use of steroids is defendable, provided that the possible side effects are controlled carefully. It is clear, however, that further evaluation of the role of steroid treatment in acquired tracheal or bronchial stenosis is required. Antibiotics have their place in the treatment of acquired tracheal or bronchial stenosis when active infection, ulceration, or granulation tissue is present. $^{212}$

\section{RECOMMENDATIONS}

The best treatment of acquired tracheal or bronchial stenosis is prevention. Therefore risk factors in developing acquired tracheal or bronchial stenosis should be avoided as much as possible. In the case of endotracheal intubation of a newborn infant, the use of an appropriately sized tube is important. Tube motion should be restricted. The routine changing of tubes is not advisable, as this may cause repeated damage. Suction techniques should be carried out with much precision, taking care not to pass beyond the tube. Infection must be treated aggressively and if oedema and inflammation occur, steroids may be of use. Supportive measurements such as moisturising the air, physiotherapy, and mucolytic drugs, are useful in treating or preventing atelectasis and tube blockage. Last but not least, as prematurity is a major risk factor, continuous efforts should be made to decrease its incidence.

\section{CONCLUSIONS}

Balloon dilatation treatment for acquired tracheal or bronchial stenosis in ventilated newborn infants is a promising method. To evaluate this technique properly, especially the long term follow up, more data are required. Studies should focus on important questions such as what type of balloon catheter is best suited, which pressures are optimum and safe, and the recommended duration of inflation. Nevertheless, in view of the successful results of four other groups of workers and of our own, we recommend balloon dilatation as the initial form of treatment in acquired tracheal or bronchial stenosis. If the cricoid ring is tight or severely damaged, however, or if the stenosis covers a long segment, other methods of treatment are recommended.

1 Cotton RT. Pediatric laryngotracheal stenosis. 7 Pediat Surg 1984;19:699-703.

2 Gould SJ, Graham JM. Acquired subglottic stenosis in neonates. Clin Otolaryngol 1985;10:299-302.

3 Healy GB. Subglottic stenosis. Otolaryngol Clin North $\mathrm{Am}$ 1989;22:599-606.

4 Dankle SK, Schuller DE, McClead RE. Risk factors for neonatal acquired subglottic stenosis. Ann Otol Rhinol Laryngol 1986;95:626-30.

5 Dankle SK, Schuller DE, McClead RE. Prolonged intubation in neonates. Arch Otolaryngol 1987;113:841-3.

6 Sherman JM, Nelson H. Decreased incidence of subglotti stenosis using an "appropriate-sized" endotracheal tube in neonates. Pediatr Pulmonol 1989;6:183-5.

7 Azizkhan RG, Lacey SR, Wood RE. Acquired symptomatic bronchial stenosis in infants: successful managemen using an argon laser. $\mathcal{F}$ Pediatr Surg 1990;25:19-24.

8 Gould SJ, Graham JM. Long term pathological sequelae of neonatal endotracheal intubation. $\mathcal{F}$ Laryng Otol 1989; 103:622-5.

9 Puhakka HJ, Kero P, Valli P, Iisalo E, Erkinjuntti M. Subglottic stenosis in neonates and children. Acta Pediat Scand 1990;79:397-401.

10 Weir N, Cuyler JP. Prolonged endotracheal intubation in neonates with hyaline membrane disease. $f$ Otolaryngo 1986;15:351-4

11 Hennequin Y, Pardou A, Detemmerman D, et al. Partia bronchial stenosis following inadvertent right bronchial intubation in a neonate. Acta Anaesthesiol Belg 1985, 3:131-6.

12 Nau TW, Gates GA, Escobedo MB. Management of neonatal subglottic stenosis. Otolaryngol Clin Norfh $\mathrm{Am}$ 1986;19:153-62.

13 Laing IA, Cowan DL, Ballantine GM, Hume $R$ Prevention of subglottic stenosis in neonatal ventilation. Int $\mathcal{F}$ Pediatr Otorhinolaryngol 1986;11:61-6.

14 Laing IA, Cowan DL, Hume R. Prevention of subglottic stenosis. F Laryngol Otol Suppl 1988;1 7:11-4

15 Brown SB, Hedlund GL, Glasier CM, Williams KD Greenwood LH, Gilliland JD. Tracheobronchial stenosi in infants: successful balloon dilatation therapy. Radiolog 1987;164:475-8.

16 Bowdler DA, Rogers JH. Subglottic stenosis in children: a conservative approach. Clin Otolaryngol 1987;12:383-8.

17 Muntz HR. Therapeutic rigid bronchoscopy in the neonatal intensive care unit. Ann Otol Rhinol Laryngol 1985, 94:462-5.

18 Lobe TE, Hayden CK, Nicolas D, Richardson CJ Successful management of congenital tracheal stenosis in Successful management of congenital tra

19 Schellhase DE, Graham LM, Fix EJ, Sparks LM, Fan LI Diagnosis of tracheal injury in mechanically ventilated premature infants by flexible bronchoscopy. Chest 1990 98:1219-25

20 Labbe A, Dalens B, Lusson JR, Dechelotte P, Meyer M Flexible bronchoscopy in infants and children. Endoscopy 1984;16:13-5.

21 Wood RE, Postma D. Endoscopy of the airway in infants and children. F Pediatr 1988;112:1-6.

22 Holinger LD, Stankiewicz JA, Livingstone GL. Anterio cricoid split: the Chicago experiment with an alternative to tracheotomy. Laryngoscope 1987;97:19-24.

23 Cotton RT. Prevention and management of laryngea stenosis in infants and children. $f$ Pediatr Sur 19i85;20:845-51.

24 Grundfast KM, Coffman AC, Milmoe G. Anterior cricoid split: a 'simple' surgical procedure and a potentially complicated care problem. Ann Otol Rhinol Laryngo 1985;94:445-9.

25 Pashley NRT. Anterior cricoidotomy for congenital and acquired subglottic stenosis in infants and children. f Otolaryngol 1984;13:187-90.

26 Groff DB, Allen JK, Greuntzig balloon catheter dilation for acquired bronchial stenosis in an infant. Ann Thorac Sur 1985;39:379-81.

27 DeVlieger H, Wilms G, Marchal G, Jaeken J, Baert A Eggermont E. Stenoses tracheo-bronchiques du nouveaune premature. Traitement par dilatation au ballonnet. Arch Fr Pediatr 1988;45:561-3.

28 Cohen MD, Weber TR, Rao CC. Balloon dilatation of tracheal and bronchial stenosis. Am $\mathcal{f}$ Radiol 1984 142:477-8.

29 Kotton B. The treatment of subglottic stenosis in children by prolonged dilatation. Laryngoscope 1979;89:1983-90. 